\title{
Can blockchain-technology fight corruption in MNEs' operations in emerging markets?
}

\author{
Matthew Davis and Thomas Taro Lennerfors \\ Uppsala Universitet, Uppsala, Sweden, and \\ Daniel Tolstoy \\ Department of Marketing and Strategy, Stockholm School of Economics, \\ Stockholm, Sweden
}

Corruption in

MNEs'

operations

\begin{abstract}
Purpose - The purpose of the study is to explore, with anchorage in theories about the normalization of corruption, under what conditions blockchain technology can mitigate corruptive practices of multinational enterprises (MNEs) in emerging markets (EMs).

Design/methodology/approach - By synthesizing a technological perspective and theory on corruption, the authors examine the feasibility of blockchain for fighting corruption in MNEs' business operations in EMs.

Findings - Blockchain technology is theorized to have varying mitigating effects on the rationalization, socialization and institutionalization of corruption. The authors provide propositions describing the effects and the limitations of blockchain for mitigating corruption in EMs.

Social implications - This paper offers a perspective for how to tackle acute business problems and social problems pronounced in international business but also prevailing elsewhere.

Originality/value - The study contributes to literature in international management by systematically exploring how and under what conditions blockchain can mitigate the normalization of corruption.
\end{abstract}

Keywords MNE, Corruption, Emerging market, Multinational enterprise, Blockchain, Smart contract, Distributed ledger, Government, Supply-chain, Subsidiary

Paper type Conceptual paper

\section{Can blockchain-technology fight corruption in MNEs' operations in emerging markets?}

A considerable risk for multinational enterprises (MNEs) when doing business in emerging markets (EM) involves corruption, here defined as the abuse of entrusted power for private gain (Transparency International, 2009). Corruption can drain funds, lead to suboptimal allocation of resources, and deteriorate trust (Rabbiosi and Santangelo, 2019). It also repels foreign direct investments and has been found to be negatively correlated to economic growth (Mauro, 1995).

\footnotetext{
(c) Matthew Davis, Thomas Taro Lennerfors and Daniel Tolstoy. Published by Emerald Publishing Limited. This article is published under the Creative Commons Attribution (CC BY 4.0) licence. Anyone may reproduce, distribute, translate and create derivative works of this article (for both commercial and non-commercial purposes), subject to full attribution to the original publication and authors. The full terms of this licence may be seen at http://creativecommons.org/licences/by/4.0/legalcode

This paper forms part of a special section "International Business in Times of Global Disruption", guest edited by Anna Earl and Elizabeth L. Rose.
} 
RIBS

32,1
Indeed, EMs represent extreme challenges for MNEs, especially because social and business practices in EMs and western markets tend to differ significantly. In these markets, corruption can work as a lubricant used to "grease the wheels" in economic exchange (Keig et al, 2015). Subsidiaries that are exposed to corruptive practices in EMs may thus become habituated to these behaviors and incorporate them into their own organizational structures (Spencer and Gomez, 2011).

Despite the growing body of research that has identified the risks and negative consequences of corruption for MNEs operating in EMs, researchers have pointed out that studies elucidating how MNEs can manage corruption remains scarce (Rodriguez et al., 2006; Cuervo-Cazurra, 2016; Stevens and Newenham-Kahindi, 2021). Rodriguez et al. (2006, p. 739) state: "Scholars have not had much to say regarding strategies for avoiding or managing corruption [...]”. While several different approaches for combating corruption are possible, the use of blockchain technology in this endeavor provides a salient forward looking-perspective for MNEs to manage corruption (Torres de Oliveira et al, 2020). Based on the premise that corruption is a social process (Ashforth and Anand, 2003), blockchain technology in particular may have the potential of breaking such processes both within the MNE organization and in its relationships with stakeholders. Blockchain technology can monitor officials' activities, digitize public services and enable corruption reporting (for example, see Bertot, Jaeger, and Grimes, 2010; Davies and Fumega, 2014; Kuriyan et al., 2011). In this capacity, blockchain technology carries transformative potential to offset opportunities for parties to act opportunistically in economic transactions, i.e. act corruptly or hide financial waste (Kshetri, 2017a), especially if matched with economic incentives designed to uphold the blockchain consensus (Tata consultancy, 2018). We propose that it is in line with this processual theoretical understanding of corruption that the implementation of blockchain technology needs to be analyzed, thereby inviting a perspective that not only takes the characteristic of the technology into account but also pays heed to social practices, discourses/ rationalizations and institutionalization processes.

While blockchain technology may facilitate legal compliance and enable global coordination of MNEs' operations, its business feasibility needs to be examined further. In general, international management literature has barely begun to systematically conceptualize the application of blockchain technology in various situations (Chabowski and Samiee, 2020; Hooper and Holtbrügge, 2020). Setting a research agenda for blockchain technology, Torres de Oliveira et al. (2020) assert that more research in the field of international management is needed to understand how blockchains can be used to ensure ethical practices in particular.

In this vein, the purpose of the study is to examine, with anchorage in theories about corruption, under what conditions the implementation of blockchain technology can mitigate corruptive practices of MNEs in EMs.

Here, we take a conceptual approach by combining international management literature and scholarship on corruption, and situate the arguments in the context of MNEs' operations in EMs. With this approach, we tackle a grand challenge of international business (Buckley et al., 2017), namely the risk of spiraling down into corruption when doing business in remote locations. Based on a conceptual framework of corruptive practices as a process - involving the parallel dynamics of institutionalization, rationalization, and socialization (Ashforth and Anand, 2003) - we deduce theoretically grounded insights regarding possible anti-corruption effects of blockchain technology. We create a categorization of three main areas related to MNEs operations in EMs: MNE headquarter-subsidiary relations, MNE-supply chain relations, and MNE-government relations. Based on this categorization we articulate propositions which describe how blockchain technology can impact corruptive practices in EMs. In doing so, we contribute to the literature about corruption in the international management field and offer a novel technological perspective involving the application of blockchain technology in EM settings. 


\section{Theoretical perspective: Can blockchain technology stifle corruption?}

In this section, we build a theoretical understanding of corruption and we also describe blockchain technology. Finally, we juxtaposition blockchain technology and MNEs challenges of corruptive practices in EMs to generate theoretically deduced propositions.

\section{The essence of corruption}

Corruption does not only include bribes, kickbacks and embezzlement but also illicit gifts, favors, nepotism, and informal promises (OECD, 2003a, 2003b; Lennerfors, 2008; Brown and Cloke, 2011; Breit, 2011). The scholarship on corruption depicts various ways in which the abuse of power is performed: a government official accepting a bribe or a kickback for his services (Rodriguez et al., 2005), to less overt and more socially embedded practices of gifts, favors and promises (Noonan, 1984; Granovetter, 2007).

Although corruption has been approached and theorized in various ways, akin to a "corruption boom" (Torsello, 2013, p. 313), corruption is usually depicted either as opportunistic behavior based on rational choice and agency theory, and thus on the individual's motivations for engaging in corrupt behavior (Rose-Ackerman and Søreide, 2011), or on a focus on the organizational structures that give rise to corrupt behavior (Heidenheimer et al., 1989; Johnston, 2005; Lambsdorff, 2007).

Within organization studies, scholars have emphasized that corruption should not only be regarded as a state, but also as a process, i.e. a stepwise institutionalization of misbehavior which contributes to legitimizing this behavior and socializing others into it in such a way that it gradually becomes normalized, into what may be called a "culture of corruption" (Ashforth and Anand, 2003). With this perspective, it is possible to understand why persons not considered to be corrupt or criminal might yet engage in or be engaged in corrupt activities (Fleming and Zyglidopoulos, 2009; Martin et al., 2009).

Ashforth and Anand (2003) is a seminal article on organizational corruption and although other articles on corruption have followed since (Anand et al., 2004, Ashforth et al., 2008), the article stands as a dominant and productive way in which organizational corruption could be understood. The article explores how corrupt practices are normalized in organizations, stating that there are three processes that together lead to normalization: institutionalization (where occasional corrupt practices become routine and embedded into the organizational memory), rationalization (that corrupt actors rationalize their corrupt actions as legitimate actions) and socialization (where new people are educated into corrupt practices).

Institutionalization, rationalization and socialization together form what Ashforth and Anand (2003) call the normalization of corruption. To fight corruption, one must therefore de-normalize corruption (Lennerfors, 2017, 2018), which according to Ashforth and Anand (2003) can be enforced by increased accountability and transparency. A premise for this article is that blockchain can be an enabler regarding this issue.

What follows from this section is that it needs to be explored whether blockchain could be a technology that breaks processes of corruption by controlling corruptive practices in MNEs, specifically by providing means to standardize ethical practices, hold individuals accountable, and make transactions transparent in line with the arguments of Ashforth and Anand (2003).

\section{Blockchain technology in the fight against corruption}

A basic explanation of blockchain rests on the metaphor of the ledger. The ledger is used in accounting for keeping track of who owns what and is instrumental to modern capitalism (Nussbaum, 1933; Yamey, 1949). But so too is trust in the ledger, which is most effective
Corruption in MNEs' operations 
RIBS

32,1

when it is legitimated by a central authority, and so centralized ledgers for property titling, contracts, and money are also critical in connecting government to modern capitalism. There is however, inherent weakness in centralization, especially if trust in the central node is lost, or external events cause a system wide breakdown. Blockchain technology enables the decentralization of ledgers and makes them verifiable, more easily accessible, and thus safe. In doing so, blockchain creates a system without single points of failure, making intermediaries and interpersonal trust obsolete (i.e. "trustless trust") (Zalan, 2018). Although blockchain technology has been described as a "truth-machine" (Casey and Vigna, 2018), trust is dependent on the quality of the underlying code, effective incentives to maintain consensus in the blockchain network, and keeping the blockchain resilient to attacks (Berke, 2017). Ultimately, the essence of the technology boils down to a need for trusting those designing and determining the context for the technology (Aarvik, 2020), making the context critical.

According to Aarvik (2020), there are four different kinds of blockchain, each with their own advantages. First, the public, permissionless blockchain is open for anyone to engage with. It is typical of cryptocurrencies such as Ethereum or Bitcoin, which rely on consensus through proof of work (PoW) algorithms. Securing the network this way requires significant computing resources, leading to high-energy consumption and scalability challenges. To counter this criticism, some blockchains operate different consensus algorithms, such as proof of stake (PoS), which aim to further democratize ownership and increase decentralization (although it has its own limitations). Ethereum, which features smart contract functionality, is currently undergoing a process to move to this proof of stake algorithm (Ethereum.org, 2020). Second, there are public, permissioned blockchains that are open for all to read, but only a permissioned group has the ability to write records due to a control layer of governance that sits on top. Security measures are simpler, transaction rates higher and energy consumption lower, since less nodes operate within the network. Third, there are closed, permissioned blockchains, where only authorized participants are granted access. Finally, the fourth variant is the private blockchain controlled by one entity. Access to this type of blockchain is strictly supervised. The functions of private blockchains resemble those of a traditional database in that control is centralized. Their records are stored in an immutable chain, though of course, the controlling authorities still have the power to dispose of or 'fork' this data at will.

The outcomes of using blockchain technology are, thus, by no means predictable because they depend on both the intent and application of the technology. Outcomes are shaped by the dynamics of the environment in which the technology is used. In ideal cases, the blockchain promises tamper-proof records that corrupt clerks or bureaucrats cannot retroactively modify or falsely notarize.

Depending on the requirements and configuration of the network, MNE's could make use of either public or private blockchain solutions, however, as mentioned there are trade-offs for each, best summarized by the so-called Blockchain trilemma (Conti et al., 2019). Most public blockchains focus on security and stability through mass decentralization, and incentivize users to participate through reward structures. Since there are many nodes which have to reach agreement, they struggle with the speed of the network (transaction throughput), and thus scalability (ability to support concurrent users). Private blockchains on the other hand, do not need mass decentralization to secure their network because only a select few have permission to engage with the ledger, hence they tend to offer better speed and scalability, and without the necessity of encouraging their participants to secure the network through reward tokens. In the case of bitcoin for example, the cost of large-scale security is high energy consumption, and a rather low 7 transactions per second (tps) 
(Garriga et al., 2020); for a private blockchains built on DLTs such as HyperLedger, this can depend on the configuration adopted by the enterprise, but speeds of 20,000 tps have been achieved (Gorenflo et al., 2020). Obviously the utility and desirability of these contrasting dimensions is dependent on the individual use-case. Hence, in this paper we do not try to solve the Blockchain Trilemma, but instead offer a perspective on how different blockchain technologies and configurations can be utilized by MNEs to reduce corruption in EMs.

Consider the example where the World Economic Forum partnered with the InterAmerican Development Bank and the Colombian Inspector General's Office to explore how the distributed ledger logic of blockchain technology could improve public transparency in school meal procurement. School meals are provided to all students in Colombia; however, the funding for school-meals has been known to be pocketed by both buyers and vendors. Applying a public (permissioned) blockchain technology opened up the public procurement process and made it difficult to cover up embezzlements and transactions that took place under the table (Barrera et al., 2019). This transparency attracted vendors to the procurement process by increasing the perception of fairness and the possibility that an outsider could win the business using clearly defined selection criteria. When monitoring actual operations once suppliers had been selected, the value of blockchain was more limited. For this purpose, the blockchain design was permissioned which reduced transparency while increasing centralization as it required transaction verification by trusted nodes (i.e. school teachers could notarize that food deliveries arrive on time and meet certain quality criteria). This experiment shows that blockchain technology needs to be adapted to the situations where it is applied which, in turn, affect its overall efficiency. In the first step of the procurement process, the implementation of the blockchain offered increased efficiency through decentralized secure transactions that lowered administrative overheads and increased transparency. In the second step involving the supplier auditing process, the blockchain could not fully replace trust since trusted nodes were assigned to govern transactions in the blockchain. While this setup did not create an automatic consensus and a decentralized system, it still provided a protocol to control transactions while simultaneously inhibiting the social processes of corruptive practices. Resting on the assumption that blockchain implementation occurs incrementally, the functionality evolves and effectiveness can be enhanced over time (Hasan et al., 2020)

There is also some evidence of blockchain technology that has been used in pilots by MNEs to fight corruption in EM supply-chains. For example, the world leading brewing giant $\mathrm{AB}$ InBev was sourcing local crops like cassava and sorghum in Uganda, as ingredients for its locally produced beers. In doing so, AB InBev had decided on a fixed price for partner wholesale-companies to pay farmers. The company, however, discovered that this protocol had been corrupted; farmers were often not getting the full price that had been promised. The company decided to onboard thousands of cassava farmers on the private (permissioned) blockchain platform (BanQu) that offered strict guidance for the "last mile" of the local supply chain. The requisite for onboarding was that farmers produced an ID card for verification and a basic mobile phone for transferring data. When they completed a sale, involving a batch of cassava, to the wholesaler they received a text message confirming the price, quantity, and money received - data that was simultaneously shared with $\mathrm{AB}$ InBev. Opportunities for corruption were, thus, choked though the transparency offered by the blockchain platform as well as through the effectiveness of its implementation (Reuters, 2019).

To sum up, the section on corruption suggests that we need to seek explanations for corrupt behavior not in the behavior of individual agents nor social structures, which is covered in the recent literature on blockchains and corruption (Adam and Fazekas, 2018), 
RIBS

32,1

but rather in processes of corruption and in the means to break these processes. We propose that it is in line with this processual theoretical understanding of corruption that any implementation of blockchain technology needs to be analyzed.

\section{The impact of blockchain technology on MNEs' corruptive practices in emerging markets}

Blockchain technology may be relevant for MNEs that need to offset corrupt behavior in challenging markets worldwide. Managing the operations of an MNE is a complex task specifically because of the presence of various types of international distance (i.e. cultural, administrative, geographic, and economic (Ghemawat, 2001). This complexity is, arguably, intensified in cases when companies make inroads to EMs. Although the business upside of entering such markets indeed could be substantial in terms of growth potential, the innate instability of these markets may create incentives for subsidiaries to get involved in corruption (Rabbioso and Santangelo, 2019).

To explain MNEs' operations in EMs in relation to processes of corruption, we break them down into three distinct dimensions along which corruptive processes will vary: i.e. headquarter-subsidiary relationships; MNE-supply-chain relationships, and MNEgovernment relationships. In the following section we will, in due order, discuss how blockchain technology may inhibit corruption in each of these dimensions.

\section{Applying blockchain technology in MNEs' Headquarter-Subsidiary relationships in EMs}

By MNE headquarter-subsidiary relationship, we denote the corruption-related internal governance challenges within MNEs that have in-house subsidiary operations, in EMs. Increased anticipated transaction costs in foreign markets (Buckley and Casson, 1976; Williamson, 1985) may incentivize MNEs to allow subsidiaries plenty of autonomy. This provides leeway for subsidiaries to conduct more efficient information acquisition, assessment, monitoring, and exchange (Rabbioso and Santangelo, 2019). Business units located offshore are however caught between the mode of operations of the headquarters and the reigning way of doing business in the local context of the subsidiary (Kostova and Roth, 2002).

MNEs from countries where corruption is not rife (to a degree that threatens basic societal functions) may be ill-equipped to tackle business exchange with actors in EMs (Luo, 2002). Corruption is likely to warp the terms of business exchange and increase the costs of processing business transactions in day-to-day operations. Corruption may be manifested by cultural practices embedded in interpersonal systems such as guanxi (Chinese), inhwa (Korean), blat (Russian) or wasta (Arabic). Such social systems can serve as the bases for business negotiations and be the sources for business opportunities; this distinction between social conventions and outright corruption may be clear to locals, but more difficult to make sense of by foreign companies making entry into the markets (Luo, 2002). Interestingly, informal social systems may emerge as a collective response to the lack of trust in formal systems (Leung et al., 2011). Hence, failing to conform to informal practices by acting within legal boundaries (such lobbying, networking and persuasion) may make companies viewed as illegitimate partners (Cuervo-Cazurra, 2016). Difficulties to control subsidiaries may be enhanced if the owner-structure is split with foreign partners in e.g. a joint-venture setup.

In a subsidiary, it might consequently be the case that corruption becomes institutionalized as proposed by Ashforth and Anand (2003). In these cases, corruption is not tied to discrete events but is part of the routines of the organization. It seems reasonable to assume that people working in subsidiaries are socialized into this organizational practice, where managers and other employees explain that one needs to play by double standards to 
survive in the market. This could be rationalized by the principle of appealing to higher loyalties (Ashforth and Anand, 2003), implying that some grey zone behavior needs to be accepted to promote the overall profitability and prosperity of the MNE. For the headquarters, such corrupt behavior can sometimes be acceptable, but one also runs a risk that these practices are brought into the light which could lead to significant negative publicity, as well as legal ramifications. This is the reason for the growth of compliance functions in organizations that are supposed to enforce adherence to corporate policy as well as legislation (Keremis, 2020).

Given the above description of the problems of the control of corruption in MNEs' headquarters-subsidiary relations, the implementation of blockchain technology within the context of compliance can secure the identity of actors that participate, or wish to participate, in economic exchange, and economic transactions will be traceable (Aarvik, 2020). This means missteps at any point in a chain of transactions can be detected and linked to individuals or machines. This setup creates a template for an efficient workflow and coordinates the globally dispersed activities of the MNE. However, within an MNE the scale of the blockchain is delimited to the global spanning organization. Full decentralization cannot be attained, as trusted nodes in subsidiaries are necessary to verify transactions (Berke, 2017). The immutability of blockchains is thus only as strong as the organization supporting the technology.

Given our theoretical framework of corruption, the choice of engaging in corruption or not is not only up to an individual. While the employees and managers might have been subjected to increasing control from headquarters, the socialization, rationalization, and institutionalization processes of the normalization of corruption need to be addressed in the implementation of the technology. There is a possibility that corruptive economic transactions of subsidiaries are kept off the blockchain (in cases where they are already normalized). In the literature, we find numerous examples of in the book entities that are controlled by the subsidiaries but whose transactions end up off the book (Momin and Parker, 2013). We claim that while the implementation of blockchain technology would have a mitigating impact on rationalization processes of corruption (i.e. constraining incentives of individuals to engage in corruption), corruptive practices would eventually be transferred (through socialization processes) into other systems effectively working around the control exerted by blockchain technology. Blockchain technology would thus only control corruption in areas of business that are specified in programmable contracts. Hence, the technology needs to be paired with a vigilant search for emerging risk-areas related to corruption. In sum, an internal blockchain for fighting corruption can support business coordination, by making sure that subsidiaries comply with pre-ordained protocols for internal business transactions. The algorithms, however, need to be carefully selected so that protocols within (private) permissioned blockchains are not side-stepped by alternative practices:

P1. Private (permissioned) blockchain technology can mitigate normalization of corruption in specified transactions pertaining to headquarter-subsidiary relationships.

\section{Applying blockchain technology in MNE-supply chain relationships in EMs}

We conceptualize business relationships in the supply-chain as those between an MNE and private suppliers or partners, not owned by the MNE, working closely together to add value and manage the flow of goods (Anderson et al., 1994; Tolstoy, 2019).

MNEs are exposed to corruption in EM supply-chains, and blockchain technology can be applied to mitigate such risks (Kshetri, 2017a). An empirical study of MNE operations in 
RIBS

32,1

Brazil by Silvestre et al. (2018) shows that supply-chains in an EM indeed can be conducive in fostering corruptive behavior. Suppliers may collaborate closely with managers of the local subsidiary leading to, in accordance with the framework of Ashforth and Anand (2003), co-optation and the conception of interpersonal off-the-book agreements. Subsidiaries in EMs may, thus, over time morally de-couple from the standards and guidelines issued by the central organization of the MNE. Some of this illicit behavior could be captured by the implementation of the internal blockchains discussed in the preceding part, given that economic transactions between the subsidiary and its stakeholders would be registered in the corporate blockchain.

The subsidiary of the MNE might counter corruption by relying on private management standard certifications (Montiel et al., 2012). Such efforts, however, have been proven to be difficult given the possibilities for suppliers to conveniently side-step control, e.g. by using consultants (i.e. decoys) to pay bribes, cherry-pick inspectors, and window-dress to pass audits as well as to accurately fill in supplier due diligence self-assessment sheets (UN, 2010). This could in turn make the MNE run the risk of malpractice (i.e. resulting in trade with conflict minerals or circumventing environmental regulations) although on paper the suppliers are compliant. Another prevalent form of corruption in supply chains is that suppliers overreport hours to increase their income (UN, 2010). Third-party architects can also receive kickbacks for designing a building or piece of infrastructure with certain kinds of materials favoring a specific supplier (Bowen et al., 2012).

Given that these are economic transactions that take place outside the ownership domains of an MNE, could it still be possible to control them within the realm of blockchain technology?

Consider the example of Volvo Cars which, together with its Chinese and Korean battery suppliers CATL and LG Chem, has implemented a private (permissioned) blockchain to ensure traceability of the cobalt that is used in batteries (cobalt is by some sources regarded as a conflict mineral). The blockchain contains the origin of the cobalt, attributes such as weight and size, traceability and information that participants' behavior is in line with OECD's supply chain guidelines (Volvo Cars, 2019). Given that the blockchain provides a pedigree of provenance, risks of corruption in other systems such as bag and tag systems where tags from non-conflict zones are available for sale on the black market [1] can be avoided. The company now aims to expand with possibilities to increase traceability of other materials, thus leveraging the partnerships to have substantial impact on business (www.electrive.com, Electrive, 2020).

Public blockchain solutions, or private blockchain platforms that are purposefully implemented around trusted partners (Tsiulin et al., 2020), can provide better workflow in the supply-chain, especially if blockchain technology is integrated with production equipment, perhaps in an Internet-of-Things setup (Kshetri, 2017b). Because the blockchain provides time stamps, and auditing linked to individual or organizational accountability, it can prohibit actors in the supply-chain to engage in fraudulent and quality-cheating behavior. Hence, blockchain technology could help shape behavior and redistribute the division of labor in MNEs supply-chain which, in turn, could result in a leaner, more disintermediated supply-chain. To preserve the immutability of a private permissioned blockchain applied in MNEs' supply-chains, incentives need to be put in place for actors not to e.g. block or manipulate consensus (Tata consultancy, 2018). Such incentives could, for example, be organized as bonuses that make it more beneficial on the margin to abide by the rules of the blockchain than not doing so (Tata consultancy, 2018). Incentives in MNEs' EM supply-chains can be organized around a proof-of-stake principle which makes it disadvantageous for suppliers to attack the consensus of the blockchain (i.e. thereby missing 
out on compliance bonuses). Another solution could be to design a strong connectivity between devices and individuals that are instrumental for work-flows in the supply chain, which would make it easier to develop effective algorithms that are safe from manipulation (Tsiulin et al., 2020).

Equal access to information and the relatively higher degree of automated trust within a permissioned blockchain to govern workflows in a supply-chain may negate the rationalization processes that underlie the normalization of corruption, e.g. the processes in which actors motivate their own corruptive behaviors (Ashforth and Anand, 2003).

Although blockchain technology has significant merits, it seems unlikely that it could break with institutionalized corruption (Narula, 2019) or completely eradicate the socialization processes of corruption underlying the formation of corrupt transactional systems. Suppliers in EMs are rarely exclusive to one buyer but are likely to contracted by many companies (i.e. H\&M and Inditex share several suppliers in Bangladesh), implying that corruption controlled (by programmable contracts) in individually managed supply chains could be limited to certain transactions or eventually transfer to other supply-chains (even create new illegitimate supply-chains), ultimately creating no benefits for society. It thus appears as if blockchain technology should be supported by collective industrial action where partners are incentivized and share the same goals (Nathan and Jacobs, 2020; Stevens and Newenham-Kahindi, 2021), to break the normalization of corruption:

P2. Blockchain technology can mitigate normalization of corruption in MNE-Supplychain relationships if a functional reward-incentive structure can be created.

\section{Applying blockchain technology in MNE-Government relationships}

By MNE-Government relationships, we denote both relations between the MNE and government in its policy-making function, and the day-to-day relations between the subsidiary and government officials (for example public procurers and inspectors). In contrast with suppliers, governmental organizations have a monopoly on public goods and services which makes them crucial to handle for the MNE.

Porter (1990) asserts that host governments influence a wide array of economic activity, i.e. industrial dynamics, demand conditions, and access to factors of production. Building on Porter's work when developing the eclectic paradigm (which remains one of the most influential models in the field of international business), Dunning (1991) claimed that governments will have a direct impact on strategic decisions related to international business, encompassing e.g. foreign direct investments, localization, and international management. More recent literature has suggested a dynamic view of MNE-government relations, implying that the interaction between MNEs and host governments is characterized by mutual dependence where MNEs seek to improve their relationships with governments (Luo, 2001; Dang et al., 2020). In the early stages of the relationships between MNEs and governments, MNEs typically set out to minimize the intervention from host governments and avoid unfavorable policies (Boddewyn, 2014). Governments on their side, especially those in developing countries, usually want to ensure a certain degree of control over MNEs to avoid exploitation (Dunning, 1998). MNEs therefore, need to maintain close ties with those dictating the rules of the game to create stability and predictability for their businesses (Hadjikhani et al., 2008; Zhu and Chung, 2014). Within this endeavor dwells the risk to become tangled up in corruptive practices.

Companies may rationalize engaging in corruption with state officials in various ways (c.f. Ashforth and Anand, 2003), for example by being able to compete on more equal terms with e.g. state-owned Chinese companies that receive industrial subsidies ( $\mathrm{Yu}$ and Zhang, 2019).
Corruption in MNEs' operations 
RIBS

32,1

At the same time, public officials and policymakers in EMs may have strong personal incentives to accept kickbacks or deals that boost their careers, especially in situations where they enjoy strong discretionary and monopoly power (Yi et al., 2019). Weak - or non-existent - governing bodies give these officials plenty of leeway to act under the radar (Khanna and Palepu, 2000). The incentives for corruption by MNEs and public officials may, thus, trigger a race to the bottom which can damage both the company and society at large.

A central area for corruption in government-MNE relations is in public procurement. Here it is possible that government officials extort the subsidiary for different kinds of favors, either to win a procurement process, or as an additional hurdle to pass after having won a procurement process (UN, 2010). In Bowen et al., 2012, some companies who pay bribes are cited, rationalizing away their responsibility by saying that it is "easier to follow the pack" and that paying bribes is an insurance to various obstacles that might otherwise appear along the way.

Echoing past research on the subject, blockchain technology indeed has the potential to steer peoples' behavior away from processes of corruption in EMs (Hughes et al., 2019), especially related to public procurement processes or in the transferring of funds where transparency is key. As witnessed in the case of the land registry in Georgia (Aarvik, 2020), public blockchains increase transparency because both material and immaterial assets and issues could be tokenized and tracked. The orderly audit of procurement processes, property rights, permissions, certificates and concessions through public blockchains can stabilize the terms of trade in the market by creating uncensored rules and protocols. However, the utility of blockchain technology requires fundamental reformations, since the resources to be recorded in the public blockchains which provide full immutability and transparency are under the wings of the government and not the MNE. The use of blockchain technology is therefore dependent on the willingness of local governments to implement supporting digital infrastructure and regulations (Kshetri, 2017a). By strengthening the transparency of government processes, blockchain technology could gain broad acceptance and make it more difficult to rationalize corruption without getting caught. Although socialization processes of corruption are likely to linger and make officials work around blockchain systems, new entrants into local government bureaucracies are indeed likely to face heightened thresholds of being socialized into corrupt schemes.

The long-term upheaval of corruption, however, needs to aim at its fundamentals. This requires a process involving both de-institutionalizing corrupt practices and institutionalizing alternative systems and practices at the government level which requires significant time, political will (Hughes et al., 2019), alignment of standards related to blockchain technology (Torres de Oliveira et al., 2020), and active mediation between major industrial players and governments (Dang et al., 2020). In short, technology alone is not likely to solve corruption as public blockchains first need to gain widespread acceptance and be implemented in a way that permeates EM governments and societal functions:

P3. Public blockchain technology can mitigate the normalization of corruption by providing transparency in MNE-Government relationships.

Table 1 sums up the transformative potential of blockchain technology for mitigating the three different processes of corruption. Effectiveness can be enhanced if Blockchain technology is widely implemented at all three levels (subsidiary, supply-chain, government) in the market.

Figure 1 is a visualization of the interfaces between stakeholders; how our propositions affect the interface, and position the MNE within an EM. While blockchain technology can be implemented in discrete relational dimensions, it may have the strongest impact in the 


\begin{tabular}{|c|c|}
\hline & MNE-subsidiary \\
\hline Rationalization & $\begin{array}{l}\text { - } \mathrm{BC} \text { has a strong } \\
\text { mitigating effect on } \\
\text { rationalization processes } \\
\text { regarding pre-specified } \\
\text { transactions of the } \\
\text { subsidiary }\end{array}$ \\
\hline
\end{tabular}

Socialization

Institutionalization

- In early stages of implementation $\mathrm{BC}$ has a weak mitigating effect on the institutionalization processes underlying corruption in the subsidiary

- In a developed stage, when BC encompasses most critical activities at the subsidiary level, it can have a strong mitigating effect on institutionalization processes of corruption (i.e. deinstitutionalization)

- De-institutionalization in subsidiary relationships may have positive ramifications for fighting corruption also in the other dimensions, especially SC and government
MNE-Supply chain

- BC has a strong mitigating effect on rationalization processes of corruption regarding pre-specified transactions in a SC

- BC has a moderate mitigating effect on socialization processes of corruption regarding pre-specified transactions in the SC

- Socialization will prevail and shift corruption to $\mathrm{SC}$ transactions not covered by the $\mathrm{BC}$

- In early stages of implementation $\mathrm{BC}$ has a weak mitigating effect on the institutionalization processes underlying corruption in the SC

- In a developed stage, when $\mathrm{BC}$ encompasses most critical activities of the industry at the industry level, it can have a strong mitigating effect on institutionalization processes of corruption (i.e.de-

institutionalization)

- De-institutionalization in $\mathrm{SC}$ relationships may have positive ramifications for fighting corruption also in the other dimensions, especially subsidiary and government
MNE-Government

- $\mathrm{BC}$ has a strong mitigating effect on rationalization processes of corruption regarding pre-specified transactions between the Government and MNE

- BC has a moderate mitigating effect on socialization processes of corruption regarding pre-specified transactions between the Government and MNE

- Socialization will prevail and shift corruption to government transactions not covered by the $\mathrm{BC}$

- In early stages of implementation $\mathrm{BC}$ has a weak mitigating effect on the institutionalization processes underlying corruption in Government transactions

- In a developed stage, when BC encompasses most critical activities at the government level it can have a strong mitigating effect on the institutionalization (i.e. de-institutionalization) processes of corruption

- De-institutionalization in government relationships may have positive ramifications for fighting corruption also in the other dimensions, especially subsidiary and SC
Corruption in MNEs' operations 


\section{RIBS}

32,1

\section{Figure 1.}

Illustration of how blockchain defends the MNE from risk of corruptive practices in an EM

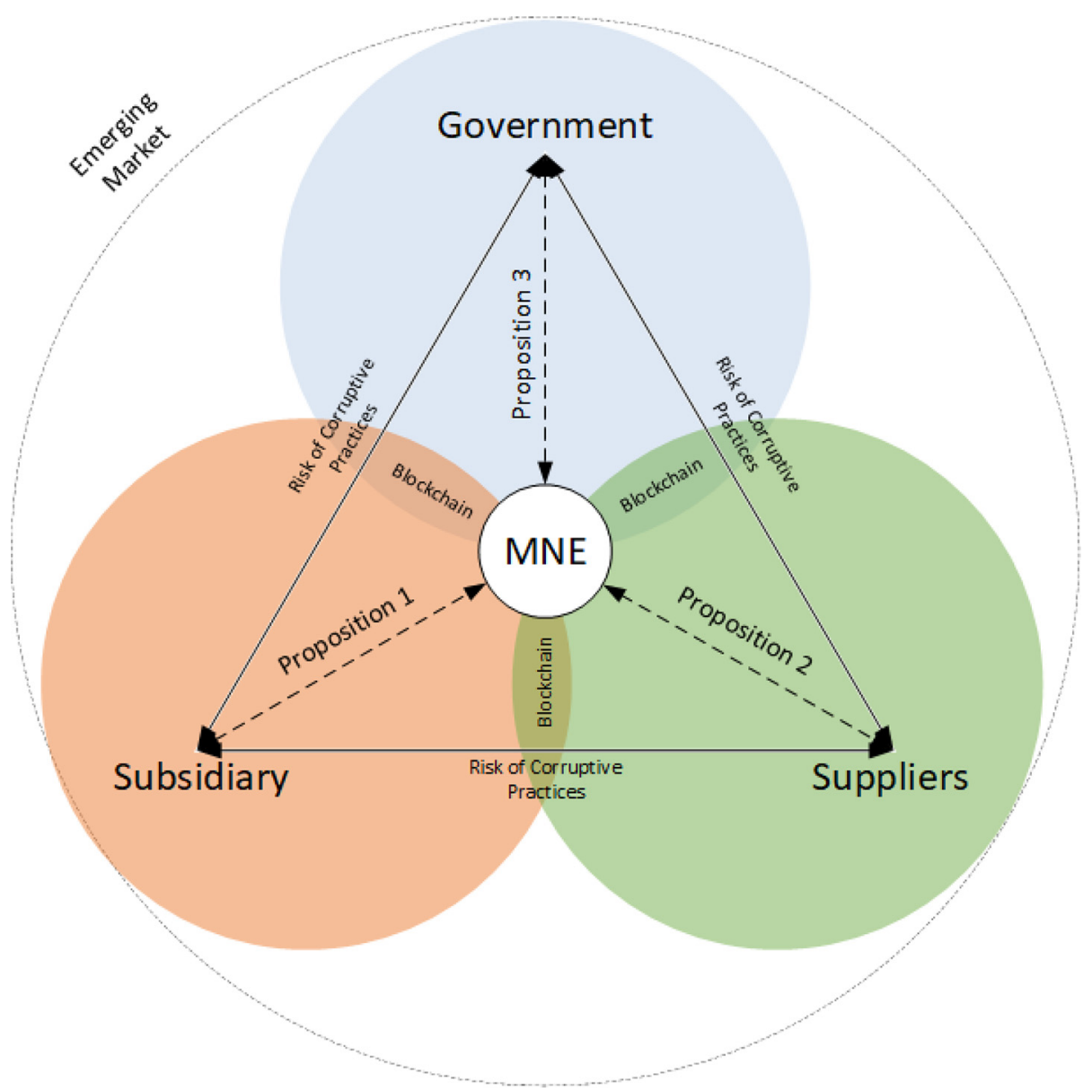

overlaps of these dimensions where leakage of corruptive processes can be prevented. Our framework is parsimonious and research implications (i.e. avenues for future research) of its delimitations will be discussed in the concluding section.

\section{Conclusion}

By juxtaposing contemporary understandings of blockchain technology and theory on corruption, we discern a potential for MNEs to use blockchain to govern and control operations in EMs. We also conclude that certain conditions need to be in place for this to happen. These conditions can be mapped in the dimensions outlined by the reasoning presented in the article.

We stress that the implementation of blockchain technology by governments is dependent on a political will (e.g. grounded in economic forecasts that promise substantial economic return in terms of additional financial resources, larger tax base, increased productivity contributing to the welfare of society) paired with a digital infrastructure. The harmonization of technological standards for blockchain is a critical issue that may require 
both supportive legislation but also broad engagement of influential companies, professional associations, and other industry associations. In cases where industrial actors are involved on a broad scale, blockchain based governance may not be confined to isolated islands in the industry that could be easily worked around, rendering a zero-net effect on corruption in society. Hence, blockchain implementation requires concerted effort where actors collectively commit to the incremental implementation of blockchain technology. In line with Stevens and Newenham-Kahindi (2021), a diverse set of collaborators offers benefits at a scale and scope that can permeate industrial sectors, decreasing the ability of government officials to interfere in MNEs' local market collaborations. The implementation of blockchain technology is an ongoing process that, particularly for permissionless blockchains, requires broad participation. In contrast, the implementation of permissioned blockchains requires continual modifications to spread incentives among participating actors as well as the creation of an organization that can withstand attacks to the blockchain. Within EM-settings, MNEs may have substantial leverage to take a lead in this development; these companies may thereby function as important orchestrators of this transformation.

Hence, building momentum for blockchain technology is likely to be contingent on gaining traction at several levels simultaneously (support at the government level, broad industrial adoption, and advocacy by influential MNEs that represent a large part of local economies). It is also contingent on purposefully designing blockchain solutions that are appropriate at different stages of technology implementation and for different use-cases. For example, permissioned blockchains in the EM supply chain may be rudimentary in early stages but grow more sophisticated over time as MNEs develop closer partnerships with trusted nodes and develop more effective incentive structures to maintain consensus.

Implementation of blockchain technology cannot convincingly be described as either a top-down process or a bottom-up process. Broad implementation will ultimately allow for a decentralization of governance. In practice this means that the power of the state and influential industry actors will move toward stakeholders and individuals and, thus, become more connected with actual business exchange (Torres de Oliveira et al., 2020). Depending on the EM, this may act as a disincentive for blockchain adoption among governments, and we see this technology driven shift in power dynamic as an important area for further study.

Revisiting the question regarding under what conditions blockchain technology can have a sustained effect on fighting corrupt practices in EMs, we zero in on the processes of corruption. While blockchain technology effectively targets rationalization and socialization processes of corruption it can also, because of its automated and real-time manner of increasing transparency, also contribute to de-institutionalizing corruption, although certain conditions then need to be fulfilled. To fully break the vicious spiral of corruption, the institutions on which these processes rest need to be deconstructed by a combination of hard law (exerted by governments) and blockchain strategies (exerted by partnerships). While blockchain can create a semi-institutionalized setting for controlling corruption in its own right (Torres de Oliveira and Rottig, 2018), it needs to be supported by market stakeholders, posing a classic collective action problem.

By offering propositions outlining how corruption can be combated with blockchain technology, we make an early contribution to international business research in this area. We encourage other scholars to draw on our insights to design empirical studies. The propositions presented here can be used as a basis to build theoretical concepts of blockchain governance and hypotheses mirroring the effects of the technology. Overall, in line with Torres de Oliveira et al. (2020), we recognize the usefulness of a technological perspective for deterring corruption and welcome studies examining the viability of

Corruption in MNEs' operations 
RIBS

32,1

Internet-of-things technology (which readily can be integrated with blockchain solutions) as well as machine learning technology. While our approach is conceptual - providing a framework setting the stage for future research in the area - we call for a more granular approach where researchers take into account the heterogeneity of EMs and study how blockchain solutions should be designed to fit the particular conditions of the market. Our reasoning offers a framework for analysis with the MNE in focus; however, it also leaves out important dynamics, possibly driving market change. This could include customers, or the general public, where innovators and early adopters solve problems by the use of blockchain technology, implying that adoption can be organic. When underground adoption individual users creating technological standards and applications - builds sufficient momentum, it can threaten traditional institutions, forcing governments to get involved in the technology. We invite researchers to expand our research by studying how such coevolutionary processes, i.e. interactions between the micro-, meso- and macro-levels, can further explain the implementation of blockchain technology.

\section{Note}

1. www.aljazeera.com/programmes/faultlines/2015/11/conflicted-fight-congo-minerals-151118084541495.html

\section{References}

Aarvik (2020), "Blockchain as an anti-corruption tool: case examples and an introduction into the technology, U4 issue. Series edited by arne strand", available at: www.u4.no/publications/areblockchain-technologies-efficient-in-combatting-corruption.pdf (accessed 11 December 2020).

Adam, I. and Fazekas, M. (2018), "Are emerging technologies helping win the fight against corruption in developing countries?", Pathways for Prosperity Commission Background Paper Series; no. 21, Oxford.

Anand, V., Ashforth, B.E. and Joshi, M. (2004), "Business as usual: the acceptance and perpetuation of corruption in organizations", Academy of Management Perspectives, Vol. 18 No. 2, pp. 39-53.

Anderson, J.C., Håkansson, H. and Johanson, J. (1994), "Dyadic business relationships within a business network context", Journal of Marketing, Vol. 58 No. 4, pp. 1-15.

Ashforth, B.E. and Anand, V. (2003), "The normalization of corruption in organizations", Research in Organizational Behavior, Vol. 25, pp. 1-52.

Ashforth, B.E., Gioia, D.A., Robinson, S.L. and Trevino, L.K. (2008), "Re-viewing organizational corruption”, Academy of Management Review, Vol. 33 No. 3, pp. 670-684.

Barrera, C., Hurder, S. and Lannquist, A. (2019), "Here is how blockchain could stop corrupt officials from stealing school lunches", World Economic Forum, available at: www.weforum.org/agenda/2019/05/ heres-how-blockchain-stopped-corrupt-officials-stealing-school-dinners/ (accessed 11 December 2020).

Berke, A. (2017), "How safe are blockchains? It depends", Harvard Business Review, p. 7.

Bertot, J.C., Jaeger, P.T. and Grimes, J.M. (2010), "Using ICTs to create a culture of transparency: e-government and social media as openness and anti-corruption tools for societies", Government Information Quarterly, Vol. 27 No. 3, pp. 264-271.

Boddewyn, J.J. (2014), "The power of concepts, typologies, theories and methodologies in IBGR research", Academy of Management Proceedings, Vol. 2014 No. 1, p. 11906.

Bowen, P.A., Edwards, P.J. and Cattell, K. (2012), "Corruption in the South African construction industry: a thematic analysis of verbatim comments from survey participants", Construction Management and Economics, Vol. 30 No. 10, pp. 885-901.

Breit, E. (2011), "On the discursive construction of corruption: a critical analysis of media texts", $\mathrm{PhD}$ dissertation, Hanken School of Economics, Helsinki. 
Brown, E. and Cloke, J. (2011), "Critical perspectives on corruption: an overview”, Critical Perspectives on International Business, Vol. 7 No. 2, pp. 116-124.

Buckley, P.J. and Casson, M. (1976), "The future of the multinational enterprise. New York: the McMillan Company Buckley the future of the multinational enterprise".

Buckley, P.J., Doh, J.P. and Benischke, M.H. (2017), "Towards a renaissance in international business research? Big questions, grand challenges, and the future of IB scholarship", Journal of International Business Studies, Vol. 48 No. 9, pp. 1045-1064.

Casey, M. and Vigna, P. (2018), The Truth Machine, 1st ed., St. Martin's Press, New York, NY.

Chabowski, B.R. and Samiee, S. (2020), "The Internet and the international management literature: its development and intellectual foundation".

Conti, M., Gangwal, A. and Todero, M. (2019), "Blockchain trilemma solver algorand has dilemma over undecidable messages", Proceedings of the 14th International Conference on Availability, Reliability and Security.

Cuervo-Cazurra, A. (2016), "Corruption in international business", Journal of World Business, Vol. 51 No. 1, pp. 35-49.

Dang, Q.T., Jasovska, P. and Rammal, H.G. (2020), "International business-government relations: the risk management strategies of MNEs in emerging economies", Journal of World Business, Vol. 55 No. 1, p. 101042.

Davies, T. and Fumega, S. (2014), "Mixed incentives: Adopting ICT innovations for transparency, accountability, and anti-corruption", available at: www.cmi.no/publications/file/5172-mixedincentives.pdf

Dunning (1998), "Location and the multinational enterprise: a neglected factor?", Journal of International Business Studies, Vol. 29, pp. 45-66.

Dunning, J.H. (1991), “Governments and multinational enterprises: from confrontation to cooperation?”, Millennium: Journal of International Studies, Vol. 20 No. 2, pp. 225-244.

Electrive (2020), available at: www.electrive.com (accessed December 11, 2020).

Ethereum.org (2020), available at: https://ethereum.org/en/what-is-ethereum/ (accessed 11 December 2020).

Fleming, P. and Zyglidopoulos, S. (2009), Chartering Corporate Corruption: Agency, Structure and Escalation, Edward Elgar, London.

Garriga, M., Dalla Palma, S., Arias, M., Renzis, A., Pareschi, R. and Andrew Tamburri, D. (2020), "Blockchain and cryptocurrencies: a classification and comparison of architecture drivers", Concurrency and Computation: Practice and Experience, Vol. 33 No. 8.

Ghemawat, P. (2001), "Distance still matters”, Harvard Business Review, Vol. 79 No. 8, pp. 137-149.

Gorenflo, C., Lee, S., Golab, L. and Keshav, S. (2020), "FastFabric: Scaling hyperledger fabric to 20000 transactions per second", International Journal of Network Management, Vol. 30 No. 5.

Granovetter, M. (2007), "The social construction of corruption”, in Swedberg, R. and Nee, V. (Eds), On Capitalism, Stanford University Press, Stanford, CA.

Hadjikhani, A., Lee, J.-W. and Ghauri, P.N. (2008), "Network view of MNCs' socio-political behavior", Journal of Business Research, Vol. 61 No. 9, pp. 912-924.

Hasan, M.R., Shiming, D., Islam, M.A. and Hossain, M.Z. (2020), "Operational efficiency effects of blockchain technology implementation in firms", Review of International Business and Strategy, Vol. 30 No. 2.

Heidenheimer, A.J., Johnston, M. and LeVine, V.T. (Eds), (1989), Political Corruption: A Handbook, Transaction Books, New Brunswick, NJ.

Hooper, A. and Holtbrügge, D. (2020), "Blockchain technology in international business: changing the agenda for global governance", Review of International Business and Strategy, Vol. 30 No. 2, pp. 183-200.

Corruption in MNEs' operations

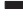


RIBS

32,1

Hughes, L., Dwivedi, Y.K., Misra, S.K., Rana, N.P., Raghavan, V. and Akella, V. (2019), "Blockchain research, practice and policy: applications, benefits, limitations, emerging research themes and research agenda", International Journal of Information Management, Vol. 49, pp. 114-129.

Johnston, M. (2005), Syndromes of Corruption: Wealth, Power and Democracy, University of Cambridge Press, Cambridge.

Keig, D.L., Brouthers, L.E. and Marshall, V.B. (2015), "Formal and informal corruption environments and multinational enterprise social irresponsibility", Journal of Management Studies, Vol. 52 No. 1, pp. 89-116.

Keremis, A. (2020), "Anti-corruption in action: How is anti-corruption practiced in multinational companies?", [Phd] 2020 (Ph.d. Serie, No. doi: 10.2020), Copenhagen Business School, Frederiksberg, p. 240.

Khanna, T. and Palepu, K. (2000), "The future of business groups in emerging markets: long-run evidence from Chile", Academy of Management Journal, Vol. 43 No. 3, pp. 268-285.

Kostova, T. and Roth, K. (2002), "Adoption of an organizational practice by subsidiaries of multinational corporations: institutional and relational effects", Academy of Management Journal, Vol. 45 No. 1, pp. 215-233.

Kshetri, N. (2017a), "Will blockchain emerge as a tool to break the poverty chain in the global South?", Third World Quarterly, Vol. 38 No. 8, pp. 1710-1732.

Kshetri, N. (2017b), "Can blockchain strengthen the internet of things?", IT Professional, Vol. 19 No. 4, pp. 68-72.

Kuriyan, R., Bailur, S., Gigler, B.-S. and Park, K.R. (2011), "Technologies for transparency and accountability”, Implications for ICT Policy and Implementation, pp. 1-67, doi: 10.13140/RG.2.2.19320.24320.

Lambsdorff, J.G. (2007), The Institutional Economics of Corruption and Reform: Theory, Evidence and Policy, Cambridge University Press, Cambridge.

Lennerfors, T.T. (2008), The Vicissitudes of Corruption: Degeneration, Transgression, Jouissance, Arvinius, Stockholm.

Lennerfors, T.T. (2017), “Corruption: maximising, socialising, balancing, and othering”, in Assländer, M. and Hudson, S. (Eds), The Handbook of Business and Corruption: cross-Sectoral Experiences, Emerald Group Publishing Limited, pp. 25-48.

Lennerfors, T.T. (2018), "Organizational anti-corruption: de-normalization through anxiety, superego, courage and justice", in Arvidsson, S. (Ed.), Challenges in Managing Sustainable Business: Reporting, Taxation, Ethics and Governance, Palgrave Macmillan.

Leung, T.K.P., Chan, R.Y.K., Lai, K.H. and Ngai, E.W. (2011), “An examination of the influence of guanxi and xinyong (utilization of personal trust) on negotiation outcome in China: an old friend approach", Industrial Marketing Management, Vol. 40 No. 7, pp. 1193-1205.

Luo, Y. (2001), "Toward a cooperative view of MNC-host government relations: building blocks and performance implications", Journal of International Business Studies, Vol. 32 No. 3, pp. 401-420.

Luo, Y. (2002), "Corruption and organization in Asian management systems", Asia Pacific Journal of Management, Vol. 19 Nos 2/3, pp. 405-422.

Martin, K.D., Johnston, J.L. and Cullen, J.B. (2009), "Organizational change, normative control deinstitutionalization, and corruption”, Business Ethics Quarterly, Vol. 19 No. 1, pp. 105-130.

Mauro, P. (1995), “Corruption and growth”, The Quarterly Journal of Economics, Vol. 110 No. 3, pp. 681-712.

Momin, M.A. and Parker, L.D. (2013), "Motivations for corporate social responsibility reporting by MNC subsidiaries in an emerging country: the case of Bangladesh", The British Accounting Review, Vol. 45 No. 3, pp. 215-228.

Montiel, I., Husted, B.W. and Christmann, P. (2012), "Using private management standard certification to reduce information asymmetries in corrupt environments", Strategic Management Journal, Vol. 33 No. 9, pp. 1103-1113. 
Narula, R. (2019), "Enforcing higher labor standards within developing country value chains: Consequences for MNEs and informal actors in a dual economy", Journal of International Business Studies, Vol. 50 No. 9, pp. 1622-1635.

Nathan, J. and Jacobs, B. (2020), "Blockchain consortium networks: adding security and trust in financial services", Journal of Corporate Accounting and Finance, Vol. 31 No. 2, pp. 29-33.

Noonan, J.T.J. (1984), Bribes, University of CA Press, Berkeley.

Nussbaum, F.L. (1933), "The formation of the New East India Company of Calonne", The American Historical Review, Vol. 38 No. 3, pp. 475-497.

OECD (2003a), Annual Report on the OECD Guidelines for Multinational Enterprises 2003 Enhancing the Role of Business in the Fight Against Corruption: Enhancing the Role of Business in the Fight Against Corruption. OECD, Paris.

OECD (2003b), "Business approaches to combating corrupt practices", OECD Working Papers on International Investment, 2003/02, OECD Publishing.

Porter, M. (1990), The Competitive Advantage of Nations, Simon and Schuster.

Rabbiosi, L. and Santangelo, G.D. (2019), "Host country corruption and the organization of HQsubsidiary relationships", Journal of International Business Studies, Vol. 50 No. 1, pp. 111-124.

Reuters (2019), available at: www.Reutersevents.Com/Sustainability/How-Ab-Inbev-Using-BlockchainImprove-Lives-Smallholder-Farmers

Rodriguez, P.L., Siegel, D.S., Hillman, A. and Eden, L. (2006), "Three lenses on the multinational enterprise: politics, corruption and corporate social responsibility", Journal of International Business Studies, Vol. 37 No. 6, pp. 733-746.

Rodriguez, P., Uhlenbruck, K. and Eden, L. (2005), "Government corruption and the entry strategy of multinationals”, Academy of Management Review, Vol. 30 No. 2, pp. 383-396.

Rose-Ackerman, S. and T. Søreide (Eds), (2011), International Handbook on the Economics of Corruption, 2nd ed. Edward Elgar, Cheltenham.

Silvestre, B.S., Monteiro, M.S., Viana, F.L.E. and de Sousa-Filho, J.M. (2018), "Challenges for sustainable supply chain management: when stakeholder collaboration becomes conducive to corruption", Journal of Cleaner Production, Vol. 194, pp. 766-776.

Spencer, J. and Gomez, C. (2011), "MNEs and corruption: the impact of national institutions and subsidiary strategy", Strategic Management Journal, Vol. 32 No. 3, pp. 280-300.

Stevens, C.E., Newenham-Kahindi, A. (2021), "Avoid, acquiesce... or engage? New insights from Sub-Saharan Africa on MNE strategies for managing corruption", Strategic Management Journal, Vol. 42 No. 2, pp. 273-301.

Tolstoy, D. (2019), "The proactive initiation of SMEs' foreign business relationships", European Management Review, Vol. 16 No. 4, pp. 1159-1173.

Torres de Oliveira, R., Indulska, M. and Zalan, T. (2020), "Guest editorial: blockchain and the multinational enterprise: progress, challenges and future research avenues", Review of International Business and Strategy, Vol. 30 No. 2, pp. 145-161.

Torres de Oliveira, R.T. and Rottig, D. (2018), "Chinese acquisitions of developed market firms: home semi-formal institutions and a supportive partnering approach", Journal of Business Research, Vol. 93, pp. 230-241.

Torsello, D. (2013), “The anthropology of political corruption: a thematic review”, Etnografia e Ricerca Qualitativa, Vol. 2013 No. 2, pp. 313-335.

Transparency International (2009), "The anti-corruption plain language guide", available at: http:// issuu.com/transparencyinternational/docs/ti_plain_language_guide?e=2496456/2028282 (accessed 11 December 2020).

Tsiulin, S., Reinau, K.H., Hilmola, O.P., Goryaev, N. and Karam, A. (2020), "Blockchainbased applications in shipping and port management: a literature review towards
Corruption in MNEs' operations 
RIBS

32,1

defining key conceptual frameworks", Review of International Business and Strategy, Vol. 30 No. 2.

UN (2010), "Fighting corruption in the supply chain: a guide for customers and suppliers", available at: https://d306pr3pise04h.cloudfront.net/docs/issues_doc\%2Fsupply_chain\%2Ffighting_corruption_ in_the_supply_chain.pdf (accessed 11 December 2020).

Volvo Cars (2019), available at: www.media.volvocars.com/se/sv-se/media/pressreleases/260242/volvocars-infor-blockchain-sparbarhet-for-kobolt-i-elbilsbatterier (accessed 11 December 2020).

Williamson, O.E. (1985), The Economic Institutions of Capitalism, Free Press, New York, NY.

Yamey, B.S. (1949), "Scientific bookkeeping and the rise of capitalism", The Economic History Review, Vol. 1 Nos 2/3, pp. 99-113.

Yi, J., Meng, S., Macaulay, C.D. and Peng, M.W. (2019), “Corruption and foreign direct investment phases: the moderating role of institutions", Journal of International Business Policy, Vol. 2 No. 2, pp. 167-181.

$\mathrm{Yu}$, M. and Zhang, R. (2019), "Understanding the recent Sino-US trade conflict", China Economic Journal, Vol. 12 No. 2, pp. 160-174.

Zalan, T. (2018), "Born global on blockchain”, Review of International Business and Strategy, Vol. 28 No. 1.

Zhu, H. and Chung, C.-N. (2014), "Portfolios of political ties and business group strategy in emerging economies: evidence from Taiwan”, Administrative Science Quarterly, Vol. 59 No. 4, pp. 599-638.

\section{Further reading}

Asongu, S., Akpan, U.S. and Isihak, S.R. (2018), "Determinants of foreign direct investment in fastgrowing economies: evidence from the BRICS and MINT countries", Financial Innovation, Vol. 4 No. 1, p. 26.

CapGemini Report (2018), "Does blockchain hold the key to a new age of supply chain transparency and trust? How organizations have moved from blockchain hype to reality", CapGemini Research Institute.

Pagallo, U. (2015), “Good onlife governance: on law, spontaneous orders, and design”, in Floridi, L. (Ed), The Onlife Manifesto - Being Human in a Hyperconnected Era, Springer, Cham.

Tata Consultancy Services (2018), "Economic incentives and blockchain security", available at: www. tcs.com/content/dam/tcs/pdf/Services/CES/Economic-Incentives-Blockchain-Security.pdf

\section{About the authors}

Matthew Davis is a PhD student at the Division for Industrial Engineering and Management at Uppsala University. He is currently studying the impact of disruptive technologies on society, of which Blockchain is one such technology.

Thomas Taro Lennerfors is a Professor and Head of the Division for Industrial Engineering and Management at Uppsala University. His research focus lies in the connection between ethics, philosophy, technology and business.

Daniel Tolstoy is an Associate Professor at the Department of Marketing and Strategy at Stockholm School of Economics. His research focus lies in the area of international business where he has studied the international operations of both large multinational enterprises as well as small- and medium-sized enterprises. Daniel Tolstoy is the corresponding author and can be contacted at: daniel. tolstoy@hhs.se

For instructions on how to order reprints of this article, please visit our website:

www.emeraldgrouppublishing.com/licensing/reprints.htm

Or contact us for further details: permissions@emeraldinsight.com 